\title{
Problems of Improving the New Paradigm of Social Processes Management in Modern Ukraine
}

\author{
Volodymyr Taran ${ }^{1 *}$, Vitaliy Dudaryov ${ }^{1}$, Hanna $\mathrm{Koval}^{2}$, Vasyl Popovych ${ }^{1}$, and Jan Holonic ${ }^{3}$ \\ ${ }^{1}$ National University «Zaporizhzhya Polytechnic», 69063 Zaporizhzhya, Ukraine \\ ${ }^{2}$ Lviv state university of life safety DSNS Ukraine, 79000 Lviv, Ukraine \\ ${ }^{3}$ Univerzita Komenského v Bratislave, 81499 Bratislava, Slovak Republic
}

\begin{abstract}
Theoretical analysis and practical application of the management system of social processes is impossible without a clear methodological basis, which is part of the paradigm. The paradigm is usually based on a system of principles that determine the prospects for the development of science. An important achievement of modern methodology of science is the theoretical substantiation of the position on the historical variability of the paradigm. This is due to the steady process of development of social practice, the expansion of the problem field of science and the improvement of research methods. It follows that any paradigm, including management, exists only within a certain time. Then it inevitably undergoes rethinking and gives way to a new paradigm. Based on this, the purpose of this article is to try to identify the most promising semantic landmarks around which to improve the new paradigm of management of social processes, and the task - to record such paradigmatic changes in the system of principles.
\end{abstract}

\section{Introduction}

Ukraine today is a young state, despite the millennial tradition of its own statehood. The fact of gaining its independence was recorded by the Declaration of the State Sovereignty of Ukraine on July 16, 1990 and acquired its final legal form after the Supreme Council of Ukraine approved the Act of Independence of Ukraine on August 24, 1991. The whole recent period of the Ukrainian state development is characterized by undoubted achievements. However, there are many miscalculations due to both objective and subjective circumstances. One of the effective levers of the state successful development is its personnel policy, especially in the field of civil service, which allows to implement strategic and tactical tasks of the state.

State personnel policy, as a component of social processes management - is a strategic activity for goal setting and software formation and development of human, labor, human resources as the main prerequisite for building a democratic, legal, social state. It determines the place and role of personnel in society, goals, objectives, the most important areas, priorities and principles of work with personnel, the main criteria for their evaluation, ways of rational use of human resources of the state. That is, the state personnel policy is the main strategy and tactics of the state in the field of formation, development and rational use of the country labor resources.

State personnel policy is a complex and dynamic institution. It depends on the type of state and the form of political system. That is, we can talk about differences in personnel policy in different socioeconomic formations (caste, class, religious, party, ethno-national, etc. approaches), as well as in authoritarian, totalitarian, aristocratic, oligarchic or democratic forms of political government. Modern Ukraine as a transitional state clearly demonstrates the complex process of transforming the personnel policy paradigm, which in reality (rather than formally) has not yet fully complied with the principles of a democratic society and retains elements of clannishness, kinship, personal devotion, regionalism, etc. previous management culture and the influence of the oligarchic system.

State personnel policy is a complex and dynamic institution. It depends on the type of state and the form of political system. That is, we can talk about differences in personnel policy in different socioeconomic formations (caste, class, religious, party, ethno-national, etc. approaches), as well as in authoritarian, totalitarian, aristocratic, oligarchic or democratic forms of political government. Modern Ukraine as a transitional state clearly demonstrates the complex process of transforming the paradigm of personnel policy, which in reality (rather than formally) has not yet fully complied with the principles of a democratic society and retains elements of clannishness, kinship, personal devotion, regionalism, etc. previous management culture and the influence of the oligarchic system.

Theoretical analysis and practical application of the management system of social processes is impossible without a clear methodological basis, which is part of the paradigm. In the philosophical context, the latter is understood as a basic conceptual scheme, a model of problem statement and solution, research methods used by scientists during a certain historical period. The 
paradigm is usually based on a system of principles that determine the prospects for the development of science, scientific industry or discipline, ways of solving problematic issues, parameters of scientific searches, criteria for the truth of research results, and the like. An important achievement of modern methodology of science is the theoretical substantiation of the essential features, structure of the paradigm, types of paradigms, as well as patterns and mechanisms of their change, which is primarily due to the steady process of development of social practice, the expansion of the problem field of science and the improvement of research methods. The analysis of these issues is reflected in the works of such leading domestic and foreign scientists as T. Kuhn, S. Tulmin, M. Alexandrov, E. Babets, P. Drucker, V. Ivanov, V. Kryzhko, M. Moiseev, G. Osovska., O. Osovsky, A. Furman, F. Khmil, Y. Yakovets and others

Thus, the position on the historical variability of the paradigm is one of the key conclusions of scientists. This means that any paradigm, including the managerial one, exists only within a certain time frame and is inevitably subject to rethinking, losing its methodological role and giving way to a new paradigm. Based on this, the purpose of this article is to try to identify the most promising semantic landmarks around which the new paradigm of social process management has to improve, and the task is to fix such paradigmatic changes in the system of principles.

\section{Results}

Speaking of the need for a paradigmatic rethinking of the principles of social governance, we can usually proceed from two levels of paradigmatic models.

The first is narrowly professional, which is based on the development and application of universal (including the most modern and innovative) principles, concepts and methods of influencing the object of social management (in this case society) in order to use its potential to achieve the goal. It is obvious that the models of this level have their own logic of development and application, focused mainly on solving the "technical" side of management. However, in the context of intensification of crisis phenomena, which today cover almost all spheres of public life, such a methodological approach is limited.

The second: worldview, which is based on the most fundamental principles methods and laws that the system of social management uses to implement the strategy of society, taking into account the current most progressive trends of civilization and national levels. Such paradigmatic models can maximally harmonize the relationship "subject - object" in the system of social management and contribute to the effective implementation of management decisions that are ultimately able to meet the interests of society as a whole.

In fact, leading Ukrainian scientists V. Andrushchenko, M. Mykhalchenko, F. Kanakh, V. Lobas, V. Kremen, S. Pazynych, O. Ponomarev, S. Farenik, S. Gudkov K. Shumovska and others are actively engaged in the search for worldview bases of the new paradigm of social process management. Their theoretical achievements indicate the existence of serious obstacles that stand in the way of forming a new concept of management paradigm in Ukraine. This is due to a number of reasons of general theoretical and specific practical nature:

- significant differences in the interpretation of basic concepts and features of management science itself: it studies management as a phenomenon that occurs in systems of different types, which are also in constant dynamics;

- the absence in the social world of laws similar to the laws of nature; here the subject of the study is constantly changing, which means that the ideas that were true yesterday may literally at one point become incapable, and even more so - erroneous [1];

- conditions of functioning of paradigms that "operate" in a certain system of space-time coordinates, where space determines a certain socio-cultural field (traditions, way of life, education system, mentality, etc.), and time - features of a specific historical moment;

- socio-cultural circumstances of the functioning of Ukrainian society, which for the whole post-Soviet period has remained a transitional society, where the horizons of the destination of its historical progress retain final uncertainty, which negatively affects the process of choosing worldview principles of social management paradigm. The latter to some extent explains why effective management paradigms that have already been tested in other countries and do not always justify the expected results in Ukrainian realities.

At the same time, the process of searching for worldview paradigmatic bases of social processes management taking into account the complex of modern problematic phenomena is marked by significant achievements, which in general express the theoretical principles of the humanistic scientific approach. This approach is focused on a radically new system of worldviews and values in comparison with the paradigmatic approach of Soviet times.

The system of government used in the Soviet Union was based on the principles of Eastern culture and was characterized by rigid centralism in economic life on the basis of state property, domination of the partystate nomenclature, lack of real economic freedom and democracy. The transition to market methods that correspond to another model of society: the existence of various forms of ownership dominated by private, market, competition, limited role of the state, expanding the rights and freedoms of economic and social actors, etc., has led to radical changes in society as a whole. This, in turn, led to a new management paradigm. According to K. Shumovska, the new management paradigm should be understood as the replacement of the Soviet (authoritarian style of leadership) with a market (democratic style of leadership) [2], which, nevertheless, is in the process of further improvement.

Such a paradigm shift in the management system orients us to shift the emphasis in understanding the 
essence of man. Thus, if the command-administrative model of government was based on the concept of "economic man", moreover, fully controlled by government and administrative structures, the marketdemocratic model emphasizes the man "social", "spiritual and creative".

Sociality in this case involves not only the ability to live and incorporate into society, but also the value category, which means the mechanism of harmonization of the individual's relationship with the group, its ability to share the values of this group and to represent the interests of this group. In a broader context, it is about the awareness of society as a complex entity, united on the basis of harmony of individual, group and social interests, the realization of which takes place in a single legal field. Hence, the effectiveness of management of social processes depends on the ability, guided by the principles of solidarity and subsidiarity, to take into account the presence of different views in society and the ability to unite them around common program objectives. The lack of such mutual understanding leads to distrust of the authorities, unwillingness to accept managerial decisions, inability to concentrate on achieving social goals, weakening statehood. Thus, in the sense of paradigmatic importance for governance, sociality is meaningfully consistent with the principles of the welfare state, which, in turn, is organically linked to the socio-market organization of the economy, developed institutions of civil society and the rule of law. This implies a focus on a certain system of principles - justice, tolerance, competitiveness, freedom, democracy, and initiative, responsibility, which are explained and enshrined at the legislative level in accordance with the course of development in the direction of the chosen state civilization model. In the sense of paradigmatic importance for management, sociality corresponds in content to the principles of the welfare state, which, in turn, is organically linked to the social-market organization of the economy, developed institutions of civil society and the rule of law. This implies a focus on a certain system of principles - justice, tolerance, competitiveness, freedom, democracy, and initiative, responsibility, which are explained and enshrined at the legislative level in accordance with the course of development in the direction of the chosen state civilization model. And this course should be clearly fixed at the level of state ideology, which should represent not only a theoretical substantiation of the basic principles of a certain state self-development strategic model, but also determine the value orientations of the main state institutions management activities in full accordance with the provisions of the basic legal documents developed and adopted by the Verkhovna Rada of Ukraine.

At the same time, it is necessary to take into account the historically determined influence of different civilizational traditions on the specifics of the formation of administrative relations in the Ukrainian state. We are talking about European (persona centric paradigm / democratic, when a person is seen as the highest value and goal (goal) for the system, when the system serves man, creates maximum opportunities for its existence and development) and Asian (systemcentric / authoritarian, when the system prevails over man, when the system has only rights, and a person only responsibilities, when a person for the system - a means, not an end) traditions with appropriate value orientations, which differently determine the priorities of the individual or team in the system of social relations. And even clearly stated in the basic legislative documents, Ukraine's orientation towards the European system of values does not deny the presence of the Asian tradition elements, manifests itself both at the level of public consciousness in the form of paternalistic sentiments, and in power structures, for which the principles of authoritarianism and monopoly sometimes look very tempting. At the same time, the choice of one of the above paradigmatic models cannot be an end in itself. Undoubtedly, the new management model in Ukraine should be based primarily on a system of values that embody the features of the historically formed Ukrainian national culture and Ukrainian national and political identity. Based on this, the relationship of participants in management activities with the cultural environment as a center of national-specific, in which, moreover, in purely managerial terms, the authority of the informal organization and the informal world is no less important than the requirements of regulations, rules, instructions from the administration. Thus, it is a question of harmonization of mutual relations between all components of administrative system within the limits of uniform national sociocultural whole.

The attitude to man as an expression primarily of the spiritual and creative principle allows us to consider the inclusion of her (man) in the management system from other positions. The essential features of such positions are due to the content of this category as a whole and its components. An important point in this context is what spirituality determines moral measurement human life, it is a living source virtues man, her morally capacity and higher value. She (spirituality) is ontological them environment man, or understood as the ability and need to assimilate and transform the external and internal world according to the laws of Truth, Goodness, Beauty in their unity .In this regard, we can say that spirituality is an important means of self-improvement and the individual and society as a whole, including as components of the management system, focusing them on the ongoing process of improving knowledge, expanding management experience, compliance with moral norms.

Creativity is understood as the more important meaning of human activity, which aims to create something fundamentally new, not similar to the previously created, activities that involve the discovery of new for this individual, and also as property of the person which is shown in all spheres of its life. In addition, it is openness to the perception and implementation of innovative approaches, without which success cannot be guaranteed in any area of social activity, including management. Spirituality and creativity are inextricably linked, their formation takes 
place in parallel, and they ultimately complement each other, which allows you to use them in a single conceptual formation, which is aimed at a large number of external and internal influences. At the same time, one more point should be taken into account: the focus on the priority of the spiritual and creative potential of a person is extremely relevant and justified in view of the fact that the main subject of the future information - society should be the "class of intellectuals" who have the main capital of the information age - scientific knowledge, combined with creativity and innovation, and the most important properties of human capital - moral attitudes. In principle, we are talking about a tendency towards ever closer interaction and interdependence of human capital, information capital, social capital and cultural capital as a necessary condition for the development of a modern information society in the broadest sense of the word [3]. As for the problem we are investigating, taking into account the characteristics of the spiritual and creative factor in conjunction with sociality, we can talk about the possibility as a whole to more effectively influence management decisions in the context of the development of an independent, democratic, social, legal state.

Identifying the features of social processes in the current environment, we cannot ignore the problem of hybridity, which has recently significantly strengthened its paradigmatic and methodological role, including directly or indirectly in the search for more effective approaches to managing these processes.

The theoretical substantiation of the objective nature of the hybridization process, which has a long history, has been continued in modern research, carried out mainly at the intersection of sciences (R. Knox, M. Brun, J. Martin-Barbero, W. Mignolo, Tha-ba Hassan, R. Bart, J.-F. Lyotard, R. Penrose, P. Gilroy, H. Bhabha, P. Verbner, D. Perkins, F. van Kappen, R. Marutyan, L. Voloshin, A. Doroshkevich, V. Gorbulin, etc.). They significantly expand our understanding of the mechanisms of such a process and show that the universal relationships, interactions, interpenetration and interdependence of different systems are carried out not only within their own structural organization or within a particular form or level of organization of the material world levels of organization of the universe as a whole. And this gives a better understanding of the role of hybridity in social processes and trends in the modern local and global world.

Despite the significant number of scientific developments that are of interest in this particular context, it is enough to refer to a few. First of all, this is a new theory of worldview - synergetics, which has taken a special place in the light of the formation of a post-non-classical picture of the world with its pluralism and dialogism ideas. Created by the German scientist G. Haken in the second half of the twentieth century, it is also known under other names - the theory of dynamic chaos in the United States (M. Feignbaum), the theory of dissipative systems in French-speaking countries (I. Prigogine), the "theory of self-organization" in Russian literature, which, however, not only do not contradict the main direction of the new science - the study of the processes of selforganization of phenomena through the use of methods of nonlinear thermodynamics, but also substantially supplement some of its provisions. It should be noted that although synergetics originated in the depths of quantum mechanics, thermodynamics, physics of nonequilibrium states and the theory of dynamical systems, it is considered an interdisciplinary science, and the subject of his interests reaches macroscopic processes and multilevel coordination, affecting various branches of natural and social cognition, including including the scope of the network information space. Moreover, synergetics blurs the insurmountable boundaries between physical and chemical processes, on the one hand, and biological and social, on the other. Synergetics focuses on the functioning of objects as open systems. Since an open system is a system that exchanges matter, energy and information with the environment, it is changeable and dynamic. Such instability of the system presupposes that it loses its previous state and acquires a new qualitative state under the influence of the environment or interaction with another / other system / systems. The latter determines the endless process of "struggle" between its two states - equilibrium and nonequilibrium - dissipative, associated with an increase in entropy (degree of complexity, chaos, uncertainty). Non-equilibrium, in turn, is able to go back to equilibrium as a new stationary state of the system [4]. So, each new stationary state, as a manifestation of the next stage of self-organization of the system, represents its new quality, acquired as a result of interchange with the environment, and can be considered as a certain form of hybridity. Moreover, in such a hybridity, through gradual internal structuring, which ensures its identity as an object with itself, there is a transformation of its previous dynamic "chaotic state", or dynamic chaos (M. Feignbaum) into "order", which, in turn, is a prerequisite for the next chain of transformations from a state of chaos to order, etc. A hybrid can also be considered as the next stage or bifurcation point in the system development. Finding a parallel between a hybrid and a bifurcation point makes it possible to talk about the multivector nature of the further possible development of any hybrid, often unpredictable, or even about the possibility of the final self-destruction of the existing system. Here, such qualitative changes in systems are also possible, which make it possible to carry out the transition from one level of organization of matter to another.

So, M. Eigen uses the principle of self-organization of matter as the main principle for biological evolution and substantiates the hypothesis about the origin of life. At the same time, he also connects it with the mechanism of movement from dynamic chaos to order within the process of transition from inanimate to living [5], which implies the emergence of certain transitional hybrid systemic formations.

Actually, the evolutionary process of the living things development as a whole can be viewed from this angle. A striking confirmation of this fact can be the symbiogenesis of L. Margulis, who added a third - 
development through symbiosis in two evolutionary directions of the global formation of life - random gene mutations and large-scale gene exchange through the global exchange network. The essence of this idea lies in the fact that symbiosis is considered as the ability of different organisms to live in close interaction with each other, which leads to the formation of new forms of life [6]. And such life forms can also be considered as hybrid in nature, which, at the same time, are certain steps in the process of its endless hybridization.

The theory of living systems and the systemic vision of life by F. Capra and P. Louise advanced scientific thought further and made it possible to reveal the universal nature of hybridity and the mechanisms of hybridization inherent in all not only biological, but also social systems, are a prerequisite for their formation, functioning and self-development, influencing both on the process of preservation of its own identity by each system, and on the nature of intersystem interaction, which does not exclude elements of the struggle for survival and domination.

The mechanism of hybridization at the social level is quite complex, because here, along with objectivity and spontaneity, the subjective factor begins to play an increasing role. It is the active purposeful activity of the social subject that ultimately determines the forms, direction of development and dynamics of those hybrid processes that can be influenced by man. It is clear that this should take into account the natural trends in the development of a particular system, including causation, as well as the presence of a factor of chance, unpredictability. Thus, in social processes, chaos and order are also subjected, in connection with which we can speak of artificial, planned, controlled chaos or organized, established order. As well as the conscious choice of attractor or "supertractor" (V. Bryansky) at the bifurcation point, which can be identified with the moment of making a management decision. Interestingly, at the level of social cognition, chaos and order are not perceived as mutually exclusive, but rather as conceptual spaces where intuitive ideas, concrete scientific interpretations and their philosophical understanding intersect, which proves a synergetic approach. Yes, and the very terminological apparatus of social synergetics, as one of the methodological foundations of management theory, is multilayered and the degree of abstraction of concepts, and their origin. This is the concept of natural sciences (bifurcation, fluctuation, homeostasis, entropy, metabolism, balance, imbalance, etc.); the concept of general scientific areas that study the laws of organization, management, technical modeling information theory, cybernetics, systems theory (system, structure, organization, information, feedback, open and closed systems, self-regulation, etc.); philosophical categories to describe more general laws and mechanisms of the development process (randomness and necessity, variability and stability); the concept of social disciplines that emphasize the specifics of the social system (order, turmoil, revolution) [7].

Interesting from the point of view of the characteristics of social objects, in our opinion, are the reasons of self-organization of socio-historical systems mentioned by G. Haken: change of global influence on the system from the environment; increasing the number of system components; mixing of components; sudden change of parameters that control [8], which, as you can see, contains signs of hybridity. Therefore, such large-scale social phenomena as unrest, revolution, perestroika, modernization, reform, etc. (as manifestations of the current state of Ukrainian society), understood through the prism of a synergetic approach, are essentially transitional - hybrid, as they contain a set of different elements that define them. Intermediate unstable state of the organization on the way to further systemic certainty, and therefore require appropriate adjustments in the management system.

Another important ideological paradigmatic principle of managing social processes can be considered eco-socialism, which follows from the concept of co-evolution (Vernadsky, P. Yerlikh, P. Raven, N. Timofeev-Resovsky, J. Tinbergen). Its actualization is due to the fact that in the conditions of globalization the problem of mutual relations and mutual influence becomes more acute human life in its bio-psycho-techno-social integrity with the natural environment, and this leads to the formation of a new quality of the universe. Violation of the balance between the components of such integrity entails deformation of the society social structure and the way of its life [9], negatively affecting in the end the political and the economic spheres of society as a whole. Such a contradiction of these processes highlights the need to create and implement the concept of a sustainable (global) society with an appropriate strategy and governance model capable of harmonizing such contradictions.

This model, which clearly correlates with the paradigm of survival (not in biological, but in its social sense) as a component of the philosophy of management (S. Gudkov) [10], focused on achieving the optimal balance between the three components of development-economic, social and environmental. Moreover, it is precisely hybridization that actively covers both each of the specified components, and intercomponent communications with all specific features of action of the hybridization mechanism carefully described within the limits of the synergetic approach. Implementation of the "global goals" of such development involves the development of management decisions in the direction of not only optimization and interconnection of economic growth, social integration and environmental protection, but also the coherence of international and national programs in economics, politics, law, technology, science, education, morality, etc., which means the adoption of a new model of world civilization, requiring the maximum level of management culture. The strategy for such development was enshrined in the UN General Assembly Resolution of September 25, 2015 [11], which is reflected in the legislative framework of Ukraine in 2019 [12] and confirmed the country's readiness to move to integrated economic, social and environmental development. 
The strategy of sustainable development is based on a number of models, which, while remaining in its value coordinate system, offer specific management ways of practical implementation of the proposed ideas. Among them, a special place is occupied by models of "green" economy, which based on the theory of R. Goldsmith on the limitation of the assimilation capacity of the environment and the need to reconsider the attitude to the economy as a whole. The difference between the "green" economy and the dominant economic paradigm today is to focus on innovative industrial production, convergence of economy and morality, overcoming the unilateral dependence of society and the environment on the economy and its synchronization with both social and natural processes [13] - use of environmentally friendly, resource- and energy-saving technologies, renewable energy sources, intangible nature management, which requires significant corrections in the management of social processes at different levels.

One of the ways to implement the strategy of a sustainable global society is the model of the "blue economy", the ideologue of which is Gunther Pauli. It is a modern business philosophy based on the logic of globalization, which represents an updated paradigm of harmonious coexistence of man and the environment, ecological and social systems. G. Pauli promotes waste-free production based on cyclicity, where the waste products of one production become the raw material basis of another. Thus, the process of coexistence and productive interaction of economic, ecological and social spheres is harmonized [14].

A variant of such an approach is the "cradle to cradle" model of M. Braungart and W. McDonagh, which involves the reuse of materials or elements of such materials to create other materials. This model works in parallel with their concept of "waste is food", by which they understand that waste from one system or process can become food or raw material for another system or process. This model is based on the principle of metabolism (metabolism between the body and the environment, which is the basis of the mechanism of hybridization) - biological and technical. A substance circulating in biological metabolism and subject to biological decomposition becomes food for other living organisms. Materials that are not biodegradable, are considered as technical raw materials and create technical metabolism [15]. Obviously, the implementation of such advanced technologies requires the formation of new thinking and appropriate organizational and managerial decisions.

\section{Conclusions}

Based on the above, we can conclude:

The need to form a new paradigm of management of social processes in Ukraine is due to a set of problems associated with the long transition state of Ukrainian society and the need to find the most effective management solutions to address these problems in conjunction with leading global trends. The basic worldview principles of the new paradigm of social process management can be the following: the priority of sociality and spiritual and creative essence of man, which contributes to the harmonization of relations within Ukrainian society and activation of creative potential of all members; awareness of hybridity as a universal means of interconnection and interaction of various intra system and intersystem elements, as well as global and national to improve their own social model; bio-psycho-techno-social integrity. These principles in general, the strategies of development of Ukrainian society, taking into account its national specifics and general tendencies of development of world civilization, correspond to the greatest extent.

\section{References}

1. L.L. Lazebnyk, V.O. Voitenko, Economics Bulletin of Dnipro University of Technology, 1, 22-29 (2020)

2. S.O. Perminova, Public administration: improvement and development, 1 (2020) http://www.dy.nayka.com.ua/?op=1\&z=1550

3. V.Iu. Lysak, V.M. Semendiak, Global and national economic problems, 21, 548-552 (2018)

4. R. Condorelli, Open Journal of Applied Sciences, 06(07), 422-448 (2016)

5. S.A. Seheda, Economy and state, 10, 14-22 (2018)

6. L. Margulis, Endosymbiosis https://evolution.berkeley.edu/evolibrary/article/hi story_24

7. V. Taran, Regional Revue, 1, 186-198 (2020)

8. H. Khaken, P. Plat, V. Ebelynh, Yu. Romanovskyi, Ob ystoryy synerhetyky. Obshchye pryntsypu samoorhanyzatsyy $v$ pryrode $y$ v obshchestve (About the history of synergetics. General principles of self-organization in nature and in society) (Institute of Computer Research, Yzhevsk, 2017)

9. R. Gloverberg, Texila International journal of management https://www.texilajournal.com/management/article /1389-the-theory-of

10. S.O. Hudkov, Bulletin of KNTEU, 1, 45-55 (2018)

11. H.T. Tereshkevych, Democratic governance, 22 (2018) http://dv.lvivacademy.com/issue/view/9942

12. Decree of the President of Ukraine of September 30, 2019, №722 "On the Sustainable Development Goals of Ukraine until 2030" https://www.president.gov.ua/documents/7222019 $-29825$

13. M. Bublyk, M. Bay, The concept of green economy and its difference from the traditional economic model (2016) http://www.economyconfer.com.ua/full-article/2055/

14. G. Pauli, The Blue Economy 3.0: The marriage of science, innovation and entrepreneurship creates a new business model that transforms society (XLIBRIS, Bloomington, 2017)

15. F. Trampenaars, P.H. Cooberg, Trompenaars Fons. 100 key management models and concepts (Mann, Ivanov and Ferber, Moskow, 2019) 